Maurice A. Deane School of Law at Hofstra University Scholarly Commons at Hofstra Law

Hofstra Law Faculty Scholarship

2014

\title{
Closing The Gap: Research, Policy, Practice, and Shared Parenting
}

Marsha Kline Pruett

J. Herbie DiFonzo

Maurice A. Deane School of Law at Hofstra University

Follow this and additional works at: https://scholarlycommons.law.hofstra.edu/faculty_scholarship

\section{Recommended Citation}

Marsha Kline Pruett and J. Herbie DiFonzo, Closing The Gap: Research, Policy, Practice, and Shared Parenting, 52 Fam. Ct. Rev. 152 (2014)

Available at: https://scholarlycommons.law.hofstra.edu/faculty_scholarship/400

This Article is brought to you for free and open access by Scholarly Commons at Hofstra Law. It has been accepted for inclusion in Hofstra Law Faculty Scholarship by an authorized administrator of Scholarly Commons at Hofstra Law. For more information, please contact lawcls@hofstra.edu. 


\title{
Closing the Gap: Research, Policy, Practice and Shared Parenting AFCC Think Tank Final Report
}

\author{
Marsha Kline Pruett* and J. Herbie DiFonzo*
}

\section{Table of Contents}

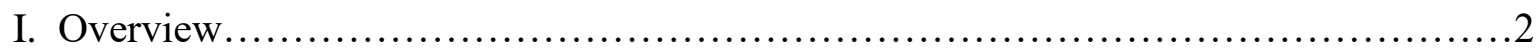

Definitions relevant to shared parenting ...................................6

II. Social Changes Leading to the Emergence of Shared Parenting as a Major Family Law

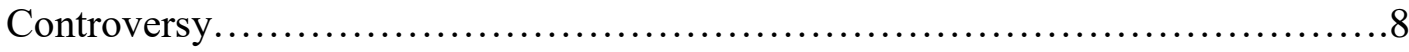

III. Legal Changes Leading to the Emergence of Shared Parenting as a Major Family Law

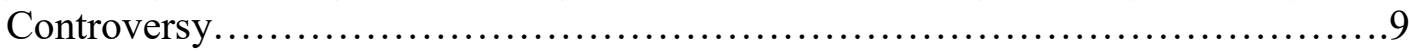

Presumptions in custody law: a brief historical introduction......................9

The current status of shared parenting presumptions.............................11

Domestic violence and "friendly parent" provisions............................12

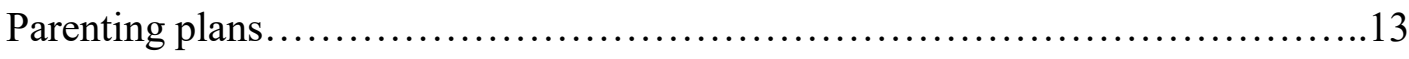

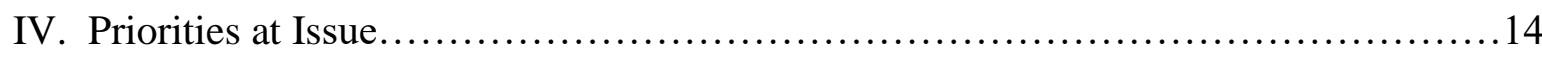

V. The Evidence Social Psychological Research Brings to Bear on Potential Policy

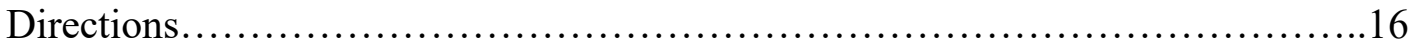

Shared parenting: sharing the parenting rather than dividing the time.............21

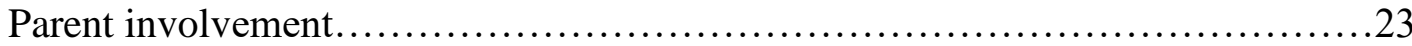

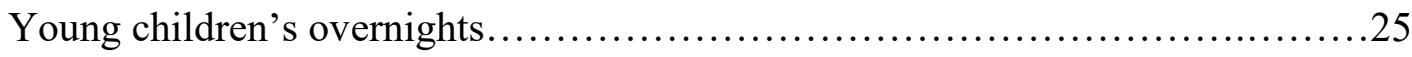

Domestic violence/intimate partner violence (IPV) ...........................26

VI. Complications in Applying Shared Parenting Research to Family Law............ 28

Making comparisons of studies that are not directly comparable .................29

Research rarely answers the specific question policy makers are trying to address.29

Recognizing trustworthy research.............................................

Static versus dynamic view of parenting ........................................ 32

VII. Presumptions and Factors about Shared Parenting and Joint Decision-making ..... 33

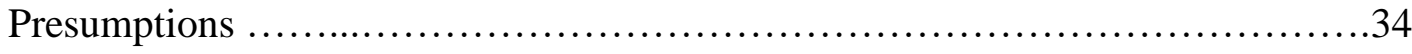

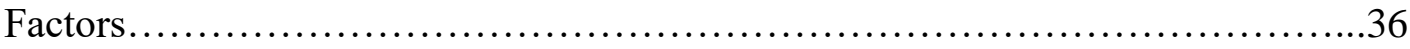

VIII. Role of the Family Courts in Shared Parenting Dispute Resolution....................37

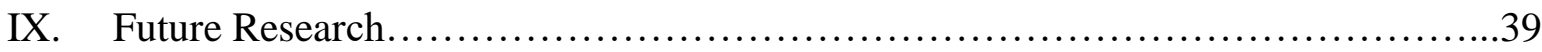


Shared parenting arrangements...................................... 39

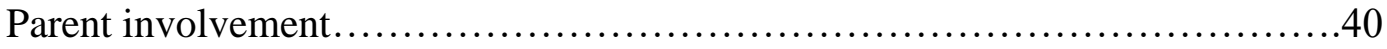

Young children and overnights.......................................41

Domestic violence/IPV .............................................41

Family court processes...........................................42

IX. Conclusion........................................................ 42

References............................................................... 43

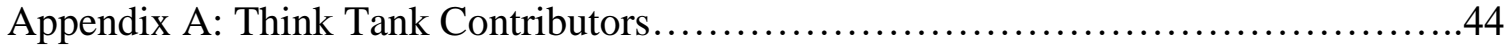

Appendix B: Points of Consensus Reached at the Think Tank......................45

\section{Overview}

Shared parenting after separation or divorce is one of the most hotly debated issues in family law today. Just as many parents are in conflict, professionals with different perspectives, experiences and educational backgrounds disagree about the best direction to take in both global family policy and particular cases. While professionals agree that children of separation and divorce fare best when they have stable, healthy and continuing contact with both parents, reaching consensus about shared parenting policy has been elusive. Professionals — as well as parents - seek guidance from both social science research and the legal system. This sensible quest must deal with two contrasting fluidities: change as experienced by individual families and the far slower flow of transformation in legislatures and courts.

Shared parenting consists of two distinct conceptual and legal entities that are combined: joint decision-making (joint legal custody) and shared parenting time (joint physical custody). Diverse opinions exist in the field about appropriate policy for each of these. Many professionals favor a legal presumption of joint decision-making, while some are opposed. ${ }^{i}$ An even wider diversity of opinion seems to exist regarding shared parenting time. One perspective is that parents should be encouraged to agree to a significant minimum quantum of time for each parent 
unless there are reasons to conclude that it would not be in their child's best interest. Others contend that shared parenting time should be the presumptive default. Still others raise concerns about the wisdom of any legal presumption, particularly in cases involving infants and toddlers, high conflict, and domestic violence. Some of these professionals take a more circumspect approach, contending that because one size never fits all, parenting time must be determined on a case-by-case basis, preferably by the parents themselves. These various perspectives have been highlighted by recent legislative activity across the globe. Shared parenting legislation has been passed in the United Kingdom, reversed in Denmark and revisited in Australia and Israel. In the United States a statute enlarging the minimum amount of parenting time was recently passed by the Minnesota Legislature but vetoed by its Governor, while a comprehensive parenting law was enacted in Arizona. Bills on this subject are under study in numerous jurisdictions, with the pace of legislative proposals increasing over the past several years.

Across the range of views about shared parenting, experts agree on the need for reliable information to better inform family courts, policymakers, practitioners, and parents. Social science research has provided much of the information relied on by the family law field, but researchers acknowledge that the types and specificity of information desired and needed is not always available. Moreover, research that is available and on point is not always interpreted or represented accurately in legal and policy advocacy processes.

With an emphasis on the role that research plays in the process of legal controversy and decision-making, as well as policy formulation, the Association of Family and Conciliation Courts (AFCC) convened a Think Tank of 32 family law experts (e.g., legal, mental health and conflict resolution practitioners, educators, judges, court services administrators, and 
researchers) to examine the issues surrounding shared parenting. ${ }^{1}$ The Think Tank focused on the gaps between research, practice and shared parenting policy, and began identifying where and how to offer guidance to policymakers and practitioners.

Challenging and at times uncomfortable discussions were held over the course of the three-day Think Tank in January 2013. It is notable that among a group of professionals selected intentionally for both their expertise and divergent perspectives, there were important points of agreement, epitomized by a majority view. These areas of agreement typically revolved around general propositions, the specifics of which were debated as points of tension with areas of disagreement and dissent noted as they arose.

\section{$\underline{\text { Regarding shared parenting time: }}$}

1. The most effective decision-making about parenting time after separation is inescapably case-specific.

2. Statutory presumptions prescribing specific allocations of shared parenting time are unsupportable since no prescription will fit all - or even the majority of - families' particular circumstances.

At variance from the majority, several Think Tank participants supported the notion of a statutory presumption of a minimum amount of time with each parent, though no optimal amount of time was specified. The concern also was expressed that while tailoring individualized arrangements would be optimal, the lack of a clear policy and the guidance it offers could result in increased incidence of interparental conflict, which negatively affects everyone in the family.

${ }^{1}$ The professionals who convened and participated in the Think Tank are listed in Appendix A. 
3. Social science research strongly supports shared parenting (i.e., frequent, continuing and meaningful contact) when both parents agree to it. There is also empirical support for shared parenting under broader conditions (e.g., some forms of parental conflict or disagreement) for children of school age or older.

4. There is no one-size-fits-all shared parenting time even for the most vulnerable families.

a) Child development professionals agreed that the current state of research allows no definitive conclusion about the impact of some or frequent overnights or no overnights, on long-term parent-child relationships and child well-being.

b) Shared parenting in the midst of high conflict is generally not in children's best interests. However, some families are able to manage the conflict on their own or with their-party assistance such that shared parenting can be implemented without harm to the children, thus bolstering the case for individualized parenting time determinations.

c) While family violence usually precludes shared parenting, there are some cases in which the violence is tied to the separation or to the dynamics of the adults' relationship while living together, and may end when the parents live apart. ${ }^{\mathrm{ii}}$ In such cases, shared parenting may be feasible. The context and meaning of the intimate partner violence and the implications for parenting must be carefully determined for each family.

\section{Regarding joint decision-making:}

5. A majority of Think Tank participants supported a presumption of joint decisionmaking, while a substantial minority espoused a case-by-case approach.

\section{Definitions relevant to shared parenting}


At the end of a traditional divorce proceeding, the court typically awarded "custody" of the couple's children to one parent. As legal custodian, that parent made all major decisions regarding the child's welfare. As physical custodian, he or she served as the residential parent with whom the child lived, while the other parent was entitled to visitation. In today's legal culture, many legislatures, courts, and mental health professionals have jettisoned these terms and recast the underlying concepts. Use of the term "custody" is rapidly diminishing. Parental responsibilities after separation or divorce are instead usually divided into decision-making and parenting time.

Decision-making refers to the legal right and responsibility to make all nonemergency decisions for a child, including those regarding welfare, education, health care, and religious training. Joint decision-making means that both parents share all parental rights, privileges, duties, powers, responsibilities, and obligations, except for specified decisions as set forth in the parenting plan. ${ }^{\text {iii }}$

Parenting time refers to the periods of time each parent spends with the child as outlined in a parenting plan or similar court order. ${ }^{\text {iv }}$ Increasingly, statutes in the United States call for parents to have significant time periods during which the child resides with or is under the supervision of each parent.

Shared parenting connotes that the parents have joint decision-making authority and that the child spends at least $30-35 \%$ of his or her time with each parent. However, the concept of shared parenting is often used without clarification about whether it is decision-making, parenting time, or both that are under study or discussion. In a meta-analysis of individual joint custody studies, Bauserman (2002) had difficulty separating out joint decision-making from parenting time as independently assessed criteria in studies; and when they were, shared 
parenting time (physical custody) was defined as "substantial" sharing with no further elaboration. Studies of representative court samples (McIntosh, Smyth, Kelaher, Wells \& Long, 2010) defined shared residential care as a minimum of $35 \%$ (5 overnights per fortnight) for all children two years and older, while Sandler, Wheeler \& Braver (in press) found $30 \%$ to be the most representative minimum level. Experts at the Think Tank agreed that joint decision making and a 30-35\% threshold of parenting time would reasonably constitute shared parenting for our purposes. $^{v}$

From a psychosocial rather than a legal perspective, shared parenting is marked by attitudes and behaviors by each parent that express a commitment to being actively involved in raising their children. Experts agree that it is highly desirable for parents to collaborate and act as a team in order to provide children with the fullest range and depth of emotional social, and economic resources that parents can pool between them. At the very least, supporting the other parent's presence in the child's life attitudinally and behaviorally fosters co-parenting involvement. But it may be possible, depending on the child's age, maturity, and other circumstance, for parents to have minimal communication and coordination and yet share the raising of their children in what "parallel parenting" (an arrangement in which parents agree to exchange important information about the child's welfare but otherwise permit each other to parent the child autonomously).

\section{Social Changes Leading to the Emergence of Shared Parenting as a Major Family Law Controversy}


The second half of the twentieth century marked a period of economic, social and political changes among industrialized nations that brought with them rapid transformation in family structures and diversity in espoused roles. Family roles traditionally structured along normative gendered lines were called into question, and prescriptions about the division of work and family among couples with children were expanded into more widely accepted variations. These shifts in roles were accompanied by higher rates of divorce among married partners and of separation among never married partners, as well as a greater incidence and acceptance of children born outside of marriage.

Although expectations that partners share work and family roles are increasingly normative, partners beginning a family often specialize in breadwinner and family caregiver roles in order to be efficient, even when both parents have paid employment (Coontz, 2006). The efficiency that sustains relationships when a couple acts to fulfill shared family goals can become the root of trouble when the couple must determine how to share parenting and family responsibilities after separation or divorce. The parent who has been the primary breadwinner for the family may demand the opportunity for equal sharing of child care and assumption of financial responsibility, while the parent who has taken primary responsibility for care giving frequently wants to retain the larger share of the child's care and upbringing and receive child support and/or other forms of financial support from the breadwinning parent. Even when both parents have actively participated in their child's care, the gendered division into roles of larger and smaller amounts of child care and responsibility play out in a similar vein after separation. ${ }^{\mathrm{vi}}$ The development of mandatory child support guidelines linking the amount of support to the parenting arrangements constitutes a significant complicating factor. The fact that increased parenting time often equates with a decreased child support obligation can serve to cloud the real 
interests of the parents and children during a time of troubling family transition, when negotiations between parents may be fraught with mixed personal motivations and/or imputation of distrust of the other parent's motives.

Among never married partners who were not romantically involved with each other for any extended period of time prior or subsequent to the child's birth, there are two common scenarios. The first is similar to one faced by divorcing parents, where the parent who has spent less time in care giving wants to increase parenting time. A second scenario may present as the parent with most of the responsibility for the child wishing to influence the other parent into taking more responsibility for the child's upbringing. Both situations involve parents seeking conflicting arrangements for legal decision-making and parenting time after the couple splits up.

\section{Legal Changes Leading to the Emergence of Shared Parenting as a Major Family Law Controversy ${ }^{2}$}

\section{Presumptions in custody law: a brief historical introduction}

For several centuries until the mid-1800s, common law courts generally awarded sole custodial rights to the father, unless the court had determined the father to be an unfit parent. In the $19^{\text {th }}$ century, American courts were confronted with two related cultural shifts: the industrial revolution's remaking men into marketplace wage earners and the emergence of a "separate sphere" for women as domestic caregivers. These courts gradually crafted a "tender years" doctrine that allocated custody of young children to their mothers upon divorce or separation.

\footnotetext{
${ }^{2}$ A more detailed treatment of the range of child custody presumptions and their legal effects is provided elsewhere in this issue (DiFonzo et al., 2013).
} 
Both the paternal preference rule and the tender years doctrine that supplanted it during the $19^{\text {th }}$ century signaled the law's conviction that after a marital breakup, children could properly be raised only by a sole custodial parent. Except in extreme cases, these legal conventions also avoided judicial evaluation of the welfare of the children whose custody was being determined. Unless the child would be placed in serious jeopardy through an award of custody to the legally favored parent, the paradigmatic custody rules at play until the late $20^{\text {th }}$ century allowed the courts to determine the result by reference to broad legal norms without reference to the particular family. The Uniform Marriage and Divorce Act, approved in 1970 and widely adopted in varying forms by many of the United States, provided an individualized best interests standard for determining child custody. The tender years doctrine weakened as courts began to acknowledge that gender roles were changing. But despite the nearly universal abolition of this presumption, many judges continue to prefer that the custody of young children be placed in the mother, who is still in westernized societies the parent who spends more time engaged directly with young children. Though remnants remain, the tender years doctrine is a relic of the common law.

An increasingly more-equitable division of parenting responsibilities, coupled with a growing unease at the win-lose mentality of custody battles and the resultant harm to children, led to a greater social and legal acceptance of no-fault divorce, mediated or interest-based settlements, and joint custody in the 1970s and 1980s. Shared parenting is today permittedindeed, often encouraged — in Australia, Canada, New Zealand, the United Kingdom, and all 50 U.S. states, although the conditions for and contours of the arrangement can differ markedly.

\section{The current status of shared parenting presumptions}


The most significant trend in contemporary child custody law is toward greater active involvement by both parents in post separation child rearing. In recent years, statutes dealing with parental responsibilities after separation or divorce have been repeatedly amended and proposals for further changes are regular features of legislative sessions across the United States and Canada. There is at present no consensus in Australia, Canada, England, New Zealand, or the United States regarding the applicability, appropriateness, or even the definition of shared parenting.

The emphasis on mutual consultation and collaboration between separated parents has led many courts to refuse to sanction shared parenting when parental cooperation and communication are severely lacking. However, some U.S. states also do not allow one parent to employ a unilateral veto on the arrangement. The general rule is that mutual hostility will not doom a shared parenting plan if the parents are committed to cooperation and are capable of setting aside their differences and/or encapsulating them from the child's witness or experience.

The vast majority of statutes, even those enacting a shared parenting presumption, avoid a specified allocation formula. Statutes continue to frame the norm for decision in terms of the best interests of the child, which almost every legislature has linked to a fairly comprehensive set of factors for the court to consider. In most cases, a shared parenting determination assures the child "frequent and continuing" contact with both parents rather than an equal or particular division of time. Trial courts retain a great deal of discretion to determine the actual distribution of parenting time.

\section{Domestic violence and "friendly parent" provisions}


Jurisdictions across western countries have legislated or found that domestic abuse renders joint decision-making and shared parenting time inconsistent with the best interests of the child. For a variety of cultural reasons, domestic abuse tends to be both difficult to detect and underreported compared to its incidence. Some commentators argue that the statutory framework is problematic because it requires the victim to prove the violence. To compound the problem, courts, practitioners and other components of the family law system often fail to acknowledge the significance of domestic abuse and minimize its extent, despite contrary legislative direction. Other commentators have expressed concern about the use of false allegations of domestic violence as a strategy to marginalize the accused parent's role and gain leverage in a parenting dispute. Similarly, concerns abound about the use of false allegations to turn a child against the accused parent and create delays in the legal process that turn into lengthy parent-child separations that have the power to undermine a previously affectionate relationship.

Many jurisdictions have added to their best interest factors one favoring the parent most willing to encourage contact with the other parent, commonly referred to as "friendly parent" provisions. Under this rubric, in determining the primary residential parent in contested cases, courts assign some weight in favor of the parent most likely to foster the child's relationship with the other parent. For example, in effectuating the principle that children should have as much contact with their parents as is consistent with their best interests, Canadian and American courts must consider the willingness of the person seeking sole decision-making or primary parenting time to facilitate contact with the other parent. This allows the court to consider which parent best recognizes and meets the child's need for a positive relationship with both parents. 
But some commentators have warned against the use of "friendly parent" provisions in cases involving domestic violence (e.g., Bailey, 2013). The problems identified include: sometimes the perpetrator may appear to be the more cooperative parent (particularly if the victim-parent is trying to prevent the perpetrator from access to the child); the victim may, in exchange for receiving primary parenting time, accept the violent partner having unsupervised periods of contact with the children; and "friendly parent" provisions can urge cooperative parenting even in cases in which parental interactions may aggravate conflict to the detriment of the child. Some statutes attempt to address these concerns by declaring that the friendly parent provision does not apply in cases involving domestic violence.

\section{Parenting plans}

Another popular legal movement has sought to re-route custody proceedings from contested hearings onto alternative resolution pathways that encourage and facilitate selfdetermination and problem solving approaches to custody disputes. A major initiative in this rerouting is the development of a parenting plan by the parents. Parenting plans have become the preferred method to achieve the public policy goal that children have frequent and continuing contact with both parents, and they are an integral component in an increasing number of shared parenting resolutions.

Parenting plans, which may be individually crafted or adapted from a menu of acceptable plans promulgated by the state courts or private sources, aim at setting out each parent's area of responsibility in providing for the child's physical care and emotional stability and well-being, both at present and as the child ages and matures. In the best of worlds, they also incorporate agreements for methods of resolving future disputes outside of court before turning to the traditional court process as a means of last resort. For example, court resources for disputing 
parents among Canadian provinces routinely suggest that parents consider mediation, collaborative law, parent coordination, and/or arbitration as dispute resolution methods should they encounter difficulties in carrying out their parenting plan. Australian law also encourages parents to take responsibility for their parenting arrangements and to use the legal system as a last resort for resolving disputes. Many American state statutes require a parenting plan as part of the process for sharing parenting responsibilities.

\section{Priorities at Issue}

The Think Tank participants articulated five statements of crucial priorities and competing tensions among children, parents, and/or the state:

\section{The child's developmental needs for stability and continuity in important relationships} with the recognition that those relationships will continue to evolve over time.

This statement refers to the will to support children's regulatory adaptations when they are very young. Children need consistent rhythms in their life that do not change frequently. Stability and continuity in relationships does not necessarily mean being cared for in a single environment, but they demand consistency in each caregiver's responsiveness to the child from one day to the next, bearing in mind that children can often adapt and benefit from differences in temperament and behavior among the adult care-givers who interact with them. The indeterminate factor is how much change is optimal, tolerable, or desirable for each child over the short and long term.

2. The child's current developmental needs with needs that will emerge over time.

As noted above, change is unpredictable. Statement number 2 frames the tension between parenting plans based on current developmental needs of children with the certainty that 
those needs will always change. Two dilemmas are present here. First, the initial legal outcome may create a status quo difficult to alter even when the developmental changes call for it, unless incorporated into the parenting plan framework. Second, setting the threshold for reopening the case in a way to facilitate appropriate change without encouraging litigation is a difficult balance.

3. Maintenance of family relationships with the protection of children from conflict and violence and the safety of both parents.

This tension between keeping both parents involved with their child in the face of emotional and often volatile separations whose trajectory cannot be accurately predicted is a major Gordian knot facing family court professionals. Moreover, when parents have been violent in the recent past, disentangling how to maintain parent-child relationships that involve the perpetrator(s) without sacrificing the safety necessary for sound parenting among the victim(s) presents another complicated picture.

4. Preservation of family autonomy through minimized interference by the court system with the protection of vulnerable family members.

The most important functions of the court entail enforcement of protections for vulnerable family members. How much to mandate protective measures while maintaining the law's commitment to non-interference in private family affairs also presents a tension.

5. Court efficiency in addressing the needs of families well and in a timely manner with meeting the complex needs of families across diverse dynamics, structures, and cultural and socioeconomic backgrounds.

Finally, family law dockets are overcrowded and understaffed, often resulting in a slow and inefficient process that exacerbates tensions within the family during the time outcomes are languishing in decision purgatory. Sometimes cases take longer than anyone involved would 
hope because the financial and/or relational issues are so complex that a great deal of time, professionals, and/or evidence gathering is needed to sort out competing views and uncovered facts. Giving complexity its due must be balanced against the tension of resolving cases without contributing further to entrenched stances that suck the resources out of families in the interim. Responding to this paradox of "hurry up and make sure you are thorough" describes the fifth tension inherent in the current family law system that affects shared parenting controversies.

Empirical and clinical knowledge serve as valuable tools for sorting out and resolving these competing interests. However, divergence within the field about how such knowledge is best understood and applied creates barriers to forming consensus and establishing policy and common practices about shared parenting. The constituents who desire clarity about how research can be used to make decisions in the shadow of these competing interests include:

○ Judicial officers, to help in decision-making;

- Legislators, to guide in the drafting of empirically informed statutes;

- Mental health, dispute resolution and legal professionals working with separating families;

- Separating parents, to inform them of the law and current legal policy basis when they negotiate their parenting agreements; and

- The wider community impacted by the laws and research applied on behalf of individual families and society at large.

\section{The Evidence Social Psychological Research Brings to Bear on Potential Policy Directions}

Without clear direction for how best to resolve these different priorities and the sociopolitical and familial tensions they engender, family law scholars and practitioners have 
looked to sociological and psychological research in hopes that it will offer guideposts for decision-making that preserve child well being in the long-term. ${ }^{3}$ Research has led to widespread agreement among professionals that children generally have improved prospects after separation and divorce when they have healthy, loving relationships with two parents before and after separation/divorce. Research has also soundly established that the multiple changes in home, school, neighborhood, etc. that often accompany separation and divorce are difficult for children, and that continuity and consistency-especially in quality parenting and parent-child relationships-support child adaptation. In particular, studies have focused on the importance for children of fathers' staying involved after separation, as fathers are more apt than are mothers to spend less time or withdraw from their children after separation. Figuring out how best to support the child's relationship with both parents while maintaining consistency and continuity in the child's life has proved challenging.

To date, shared parenting research has not been utilized sufficiently or accurately as a springboard for advice to policymakers faced with competing interests and claims about what is best for children after separation and divorce. Is there statute-worthy science? What does relevant research, considered in the aggregate, point to as policy directions that best support interests of children and families? There has been no clear articulated position from involved professionals across disciplinary and theoretical perspectives. In response to this void, policymakers are making decisions based on pressures brought to bear by various constituent groups, concepts of "fairness" and anecdotal evidence from highly litigated cases, rather than on accumulated social science knowledge.

\footnotetext{
3 Throughout this article, we summarize research central to the Think Tank discussions. In order to keep the text to a manageable length, and because this is a Report and not a research article, we provide citations sparingly. We do not cite individual studies (with one exception in the "overnights" section) but instead identify relevant reviews. When we present statements attributable to an author, we provide citations.
} 
Throughout this report we present points of consensus that emerged in discussions as policy-worthy for their salience and their backing by at least a majority of Think Tank participants. Our first point centers on beliefs about the importance of shared parenting as a policy cornerstone for family well-being.

Consensus Point 1: Promotion of shared parenting constitutes a public health issue that extends beyond a mere legal concern. Parents who collaborate in child rearing have a positive effect on their children's development and well-being. Parents who engage in protracted and/or severe conflict that includes rejecting or undermining the other parent have a negative impact. The potential for shared parenting is present for children regardless of the family structure in which they live, and it represents a key protective factor in (a) helping children adjust to separation and divorce and (b) establishing an ongoing healthy family environment in which to rear children and facilitate high quality parenting.

As interdisciplinary professionals involved in family law, Think Tank participants agreed that our mission involves educating all families about the value of shared parenting that is carefully developed and maintained over time. Shared parenting has inherent benefits for the entire family, but the risks of ongoing conflict and of making compromises that are not child-centered in order to placate one parent's desires for "equal" parenting over the other's objections must also be recognized. Preventive measures against such risks must be delineated so that protections can be made available. Policy debates are often framed as competing choices between maximizing the potential benefits of shared parenting and minimizing the potential risks. We framed two questions as underpinning key policy controversies:

1. Do we fear the potential harm caused by inappropriate use of shared parenting more than the harm potentiated by a lack of shared parenting when it is appropriate?

2. How does research help us establish where the benefits and harms to children in shared parenting lie? 
To answer these questions, we began by recognizing that social science research has played a critical role in shared parenting throughout its evolution as both a conceptual frame and legal possibility. Research has contributed volumes to understanding the following family characteristics and dynamics both directly and indirectly relevant to shared parenting:

a) child development at various stages and its relationship to separation/divorce adjustment;

b) contributors and barriers to high quality parenting - notably parental mental health, characteristics of successful co-parents and co-parenting interactions;

c) the protective factor of cooperation and the risk factor of parental conflict;

d) the specification of various types of family conflict and their harmful and - in cases of protracted and high level conflict that is witnessed by and/or involves the childrendestructive force for children's well-being;

e) the sustaining capacity of positive father involvement;

f) influences of re-partnering and having children with a new partner;

g) interventions that foster parental well-being, sensitive and appropriately structuring parenting, a positive co-parental relationship, dual parent involvement, reduced conflict; and

h) the role of alternative dispute resolution in general and mediation in particular for fostering co-parenting agreements and promoting familial self-determination of postseparation arrangements and decision-making.

In each area, research has provided enhanced understanding of the broad brush strokes relevant to shared parenting and some of the specific conditions under which parental sharing works well or works poorly for children of varying needs and developmental eras. The interdisciplinary group at the Think Tank recognized both the value and the limitations of applying research findings within family law. In particular, we highlighted two areas: 
Consensus Point 2: At its most influential, research evidence offers legal professionals and clinical decision makers the best available information without providing answers or predictions in any individual case. However, when aggregate-level research is applied as determinative of a specific case outcome, its value becomes compromised in the adversarial process.

Research becomes part of the problem rather than the solution when it is used as a hammer instead of a level. When empirical knowledge is used to nail down points of evidence rather than to provide a point of balance from which to draw conclusions based on other relevant information, it loses its potential to provide clarity in the highly subjective world of legal negotiation and decision-making. When an area of research is used to typify an all-encompassing standard rather than a point at which to begin asking questions, we immediately run the risk of undermining its contribution of identifying probabilities based on particular factors or circumstances.

Consensus Point 3: We need to differentiate areas with sufficient research to offer consensus in legal situations from those without a sufficient data basis or agreement about its interpretation. Only then can consumers of research distinguish the quality of individual studies and the authority of an aggregate body for assisting in decisions.

Some areas of research are established with sufficient quantity and quality of information to offer bright line recommendations (e.g., the effect and conditions under which conflict undermines children's positive development), but these must be distinguished from studies that offer preliminary information yet do not create an adequate body of research to suggest a policy direction for a broad subsection of family populations. For example, areas of research with strong supporting bodies elucidate both the harm to children due to continued exposure to parental conflict, and the important protective factor of positive quality parenting by both parents. In contrast, under what conditions and how best parents in moderate conflict can 
continue to share decision-making and parenting time exemplifies an area about which we do not have a sufficient body of knowledge to recommend policy. Similar concerns underlie the question of when having children alternate between two homes on a regular basis becomes more anxiety producing than beneficial.

With these refrains in mind, we turn to brief synopses of the relevant research literatures in order to lay out critical issues defined in the Think Tank. Four bodies of work were identified as central to the discussion. The first includes direct studies of what is commonly referred to as joint custody, be it physical (residential) or legal (decision-making), and sketches what we know about shared parenting and its efficacy for children. For comprehensive texts on the subject, see Kuehnle \& Drozd (2012); also see Kline Pruett \& Barker, 2009; Kelly, 2007). Following this synopsis of shared parenting research, we turn to three areas that flag vulnerable subgroups and dynamics in the family after separation: (1) parent involvement and behavior by one parent that interferes with or undermines the child's relationship with the other parent; (2) infants and toddlers whose shared parenting schedules include overnights at the less-seen parent's home; and (3) shared parenting in the context of prior or current family violence.

\section{Shared parenting: sharing the parenting rather than dividing the time}

Parenting plans allocate decision-making and parenting time. Though there is little evidence on the outcomes of children when joint decision-making and shared parenting time arrangements are carefully differentiated, research by and large confirms that when parents freely choose to be in shared parenting situations, family members show positive adjustment. Parents who choose these arrangements have reported that their children are better adjusted across multiple measures than their sole-custody or stepfamily peers. These trends have held internationally across cultures and countries. 
Considered as a body of work, the efficacy of shared parenting has been supported for children preschool and older. But how much time allocation makes a difference for or against positive development is as yet unknown. Moreover, any benefits of shared parenting may well be reduced or even reversed in vulnerable circumstances (i.e., younger children, high conflict, court mandated sharing). This prevents the framing of confident conclusions about whether shared parenting can be successfully adopted and implemented in any given situation. The sheer number of potential intervening factors, let alone their balance, outstrips the current knowledge base.

The focus on a division of parenting time obviates the most important element of shared parenting. Shared parenting time is ideally constituted by organizing complementary schedules that support the healthy functioning of the reconstituted family. Think Tank participants shared the view that in an optimal parenting plan, responsibilities and time are not allocated according to a principle of abstract fairness to the parents, but by family functionality (e.g., how each parent's work schedule coincides with the child's school and activity calendar) as it relates to the child's best interests.

As a result, participants at the Think Tank cautioned that the nuances apparent in the current literature on parenting time call for parental agreement or individualized judicial assessments rather than decisions premised on legal presumptions. Parents who do not attempt to remove themselves or their children from conflict, who do not commit to supporting the presence of the other parent in their child's life, or who are unable to collaborate in making mature decisions that are truly child-centered are typically not considered appropriate for shared parenting arrangements (unless they can agree sufficiently and safely to raise the children with "parallel parenting" strategies). On the other hand, there is enough research to conclude that children in families where parents have moderate to low conflict and can make cooperative, 
developmentally-informed decisions about the children would clearly benefit from shared parenting arrangements.

\section{Parent involvement}

As child development research has been concentrated most often on mothers as parents, parent involvement research after separation has typically focused on fathers (For reviews, see Amato \& Dorius; 2010; Fabricius, Braver, Diaz \& Velez, 2010; Kline Pruett, Pruett, C. Cowan, P. Cowan \& Diamond, 2011). Relationships between biological fathers and non-biological father figures who are important to the child in their role as "father" and caregiver are implicated in dynamics that strongly impact family adjustment after separation. Given that mothers are the more prevalent residential parent across countries and family structures, the issue of how—and how much - fathers can stay involved with their children after separation lies at the center of current debate over shared parenting. Research about parent involvement is one of the more robust literatures that have developed in the past generation. In a nutshell, positive parent involvement that combines nurturing with sensitive but effective discipline proves beneficial for children. And as noted above, shared parenting arrangements can ameliorate the negative effects of lessened father contact and involvement associated with parental separation.

Despite the extensive list of advantages to positive father involvement, separation from and uninvolvement with the child's mother fuel a number of family dynamics that combine to pose obstacles to continued father involvement. One problematic dynamic arises from parental gatekeeping, which characterizes one parent's control over the extent to which the other has access to their child and to information that facilitates their involvement, such as school and medical information. Maternal gatekeeping has again received more attention in separated families than paternal gatekeeping. Studies have repeatedly shown that the strongest predictor of 
father involvement is not the father's desire or intention to be engaged, but the mother's desire to have him involved. She thus has a great deal of power in regard to the type and amount of access he has to the child if he is not living much of the time with the child. Other factors that contribute to father involvement attenuation include pain of separation that leads to paternal withdrawal, and involvement with new partners, children of those partners, and having children with those partners. Additional adverse factors include inexperience or ignorance about parental rights (especially among unmarried and/or teen parents), as well as institutional and societal barriers that still make it difficult to parent outside of an intact family. All of these factors suggest that it is more difficult for men than women to stay committed to parenting after separation, but it is important for the family system that they do so when they are motivated to be loving, engaged parents.

It is also well understood that any parent loss presents a risk factor for any child. These consequences result in part from losing child rearing, financial and community resources normally combined in an intact household. Father absence due to divorce has been associated with poorer child and adolescent outcomes. Shared parenting arrangements in studied populations have mitigated these effects and benefitted children's family relationships, economic stability and social capital.

Shared parenting is one way of securing fathers' rights and abilities to be involved with their children by affording them time and opportunities in ways that reinforce their sense of authority, value, and significance in the life of their child. Joint decision-making and shared parenting time can ease a father's fear of losing his parental role and/or sense of belonging in his child's life. Think Tank participants agreed that having parenting time that is not solely on 
weekends typically contributes to higher quality parenting and more enduring relationships with children; a handful advocated further for a norm of equal sharing.

\section{Young children's overnights}

Embedded within the shared parenting research is a hotbed of controversy on the question of overnights for fathers with very young children who do not primarily reside with them. As indicated, early paternal involvement serves as a protective factor for later father-child relationships. Yet the primacy of attachment research paradigms for mapping the pathway to healthy development has led to dyadic considerations of security and stability that have, until very recently, excluded the father or other caregiver. The emphasis on assisting parents through a conflict-laden transition, while their children's brains and minds are developing rapidly and in need of consistent nurturance and support in order to develop physiological and biological regulation and trust in the world around them, can pit the uncoupling family's dynamics in direct opposition to the child's capacities and needs. The question of stability is one of perspective: a child loses the stability of consistent nighttime routines and comfort taken from a relied upon caregiver, or the nurturance at those times from an other parent. The relative loss and corresponding instability created for the child depends in part on how distinct or overlapping the caregiver roles were at night prior to separation. The question of how to negotiate these critical and sensitive junctures in family life has led to controversy in legal arenas, with research scarce and very limited in terms of generalizability. In this Think Tank, we only began to sketch out the issues of controversy and sift through them, arriving at a few points of agreement.

Consensus Point 4. Infancy is an important time of rapid growth and foundational development. During this time, sensitive caregiving is critical to maximize the child's immediate and long-term well-being. Special consideration needs to be given to meeting young children's developmental needs. 
Consensus Point 5. Children benefit from parents sharing in their upbringing throughout their life span, where appropriate, including in the earliest stages of life.

Consensus Point 6. When there is a dispute over a young child's care, decision makers (including parents) should consider all relevant factors. No single factor trumps the influence and importance of the aggregate.

Discussion about how best to ensure the twin and at times competing priorities of both parents' involvement and the young child's stability stalled, although the group agreed that these two priorities are not always mutually exclusive as so often described in the literature or in individual cases. While no consensus was reached about how to reconcile these competing developmental concerns, Think Tank participants identified the relevant factors that must be accounted for in order to balance them in any particular case. These are discussed in the next section of this Report. Additionally, McIntosh, Pruett, \& Kelly (this issue) have taken steps to incorporate both priorities in policy recommendations that build upon the general propositions arrived at during the Think Tank.

\section{Domestic violence/intimate partner violence (IPV)}

Think Tank experts agreed that when either or both parents have been violent through physical, verbal, or psychological abuse of the other parent, a comprehensive assessment is necessary before a shared parenting plan is considered. A substantive body of research makes clear how destructive such violence can be to parents' ability to raise their children with the requisite sensitivity and structure that promotes victim and child safety and well-being. In addition to diminishing parenting capacity, family violence negatively affects children's wellbeing directly. When children are directly involved in the conflict or are the subjects of it, the probabilities for their healthy development are far worse. 
Think Tank discussions acknowledged that even violence is not a clear presumptive factor against shared parenting as it might appear. Individualized considerations bear on assessing the impact of family violence for shared parenting. Namely: When and how the violence occurred (frequency; severity; distant or recent past versus present; separation-specific or not; perpetrated by one family member against another or part of an ongoing family dynamic); whether and how the child can be insulated from it; the child's prior and current relationship with the perpetrator(s); and whether some controlled contact promoted under conditions of safety will help support both the child's capacity to cope with his/her family situation and the violent parent's capacity to draw on his/her nurturing capacities to strengthen the parent-child relationship without endangering the child or the child's other parent.

What the victim-parent(s) faces in shared parenting is of paramount concern. The cooperation or communication that is inherent in making decisions jointly or moving children between two homes creates countless opportunities for the perpetrator to continue patterns of manipulation, violence and control on the other parent. Shared parenting can be structured to keep parental contact at a minimum, through carefully structured parenting plans and separating decision-making authority across major domains. But it still increases the danger of one parent being able to lord fear, threat, intimidation, or other forms of power over the other, while using the children as pawns in order to secure the other parent's compliance or hurt the other parent by manipulating the children to reject the parent.

Given this omnipresent possibility, the Think Tank participants supported caution in considering any shared decisions or arrangements when IPV is/was involved. Moreover, a legal presumption in favor of shared parenting would task parent-victims with the obligation of countering a rebuttable presumption that would further burden this already vulnerable group of 
parents. The abuse might not be established, as IPV is not always uncovered through screening and evidential inquiry. Furthermore, many professionals familiar with domestic violence dynamics emphasize that victims often fear angering their perpetrators and increasing the risk of further abuse, so IPV goes underreported. Parents who have been abused and are already feeling disempowered vis-a-vis the abusing parent are often unwilling to risk appearing to be the uncooperative parent in a legal dispute, therefore putting themselves potentially at a disadvantage in negotiations. For all of these reasons, there was general agreement on the need for individualized assessments. Moreover, a complicating factor in evaluating some IPV cases is the risk posed by false allegations aimed at manipulating the legal outcome. Comprehensive summaries of the IPV issues involved in potential shared parenting situations can be found in (Hardesty, Haselschwerdt \& Johnson, 2012; Johnston \& Ver Steegh, 2013; Ver Steegh \& Dalton, 2008; Hannah \& Goldstein, 2010). In addition, Brinig, Drozd \& Frederick (this issue) provide a full consideration of presumptions and factors that warrant specific and careful weighing when IPV is or has been present in potential shared parenting situations.

\section{Complications in Applying Shared Parenting Research to Family Law}

The Think Tank discussions encompassed parameters for using social science research to assist legal decision makers in shared parenting cases. As noted above, in some areas relevant to shared parenting research, we have larger and more consistent bodies of knowledge. The Think Tank participants recognized early on, however, that cross-pollinating science and practice or policy has inherent pitfalls. Social science research provides a starting rather than ending point for policy development. Appropriate reflection on research contexts will help prevent the 
misapplication of data in broad sweeps to all individuals. Some of the pitfalls encountered and ways to avoid them include the following:

Making comparisons of studies that are not directly comparable

Even when individual studies are sound, the individual studies or accumulated literature gets distorted when it is interpreted. For example, in the overnights literature, three major studies

are often cited on overnight studies (Solomon \& George, 1999; Kline Pruett, Ebling \& Insabella, 2004; McIntosh, Smyth, Kelaher, Wells, \& Long, 2010). Comparisons of these studies have lead to distorted conclusions that results from faulty assumption made that these studies look at similar outcomes measured in similar ways, which they do not. Responsible scholarship acknowledges and elaborates on these differences so that they are clearly articulated.

\section{Research rarely answers the specific question policy makers are trying to address}

The difficulty remains in the translation from science to policy, or from social science to law. Research studies may point to a desired direction for family relationships (e.g., keeping the father involved), but the studies themselves do not shed light on how that direction is to be reached. Accepting that both parents are important to child adjustment when parents live apart, and that their involvement in shared parenting promotes child adjustment, does not address how parents best become and stay involved. Some parents choose not to be or to stay involved, while others find their role circumscribed until their involvement is reduced or prevented altogether. The unsettled policy issue lurking behind the "how" question is whether reluctant or excluded parents can achieve full participation in child rearing without a statutory time specification. 


\section{Recognizing trustworthy research}

Science endeavors to be objective, above taking sides in a controversy. This is of course, a fallacy, as researchers bring their own biases to the process in the form of their beliefs about human nature, how they form their questions, what variables they select to investigate, and how they interpret their results. The purpose of utilizing research to clarify policy options is to obtain a more objective standpoint than that propagated by advocacy groups. Relying on trustworthy research further reduces the risk of it being used inappropriately for political reasons. While a comprehensive treatise is beyond the scope of this report, a few tips can help maximize the selection and appropriate use of reliable research.

First, stick to the selection of peer-reviewed studies. A rigorous peer review process in social science is designed to minimize biases. The process requires each study to undergo review from several anonymous peers, presumably with relevant expertise, whose goal is to pick apart the study in sufficient depth that biases will be stripped away and methodological deficiencies will be corrected if possible, and acknowledged in any case. Studies that have not been subjected to this process (reports, research summaries, magazine publications, some — but not all—book chapters) should be considered with appropriate skepticism and relied upon conservatively.

Second, consider significant as well as non-significant results. Often a large amount of attention is garnered from one finding, when most of the variables investigated were not statistically significant. If shared parenting was related to greater incidence of externalizing behavioral problems, but had no bearing on internalizing behaviors, social skills, self-esteem, or parent-child relationships, the risk should be assessed as a real but contained one, and the one negative effect should not be presented without reference to the other non-significant findings that are equally telling. Moreover, a significant effect may not be an important one in real world 
application. Two variables may be related to a significant degree, but still only co-occur 1 in 5 times in the real world. A public policy should not be based upon the conjunction of factors that will not be connected 4 out of 5 times they are assessed. Similarly, when scores on outcome variables differ significantly between two research groups but fall within the normal range, the differences are less relevant for public policy. Children in shared parenting arrangements may differ from those who are not on attachment security, for example, but both percentages may still fall within the norms for attachment security in the general population. Depending on other factors pertaining to the child's individual and family well-being, the finding may not be sufficient around which to construct a public policy.

In addition, research reports should consider alternative explanations for results. A common error in interpretation occurs when association is implied to mean causation; two variables that co-occur such as positive father involvement and child academic achievement do not prove that father involvement leads to school success. In fact, children whose fathers are highly involved may be more likely to value education for other reasons, or both factors may be related to socioeconomic status or better partnerships with the children's mother.

Trustworthy studies in this field garner information from both parents to the fullest extent possible, rather than relying solely on mothers' or fathers' reports. Trustworthy research uses measurement instruments and procedures with proven reliability and validity, and the study methods fit the policy-related question. For example, it is known widely that the "Strange Situation," a research paradigm used to assess attachment in young children, is less valid for fathers than mothers. Studies of married, white middle class parents cannot be assumed to be applicable to low income families or parents of color, and vice versa. Comparing overnights in a sample of children who rarely saw their fathers before separation with one that lived with them 
continuously will likely produce different group results which are not necessarily attributable to the overnights; pre-existing conditions in the families that must be taken into account.

Even if a study provides ample context to know that it was conducted with best practices and appropriate disclaimers are made about not over-interpreting the research, studies become cited by press releases, journalists, and other authors who may choose a part of a study to describe, may report findings without including methodological cautions raised by the author, may downplay or accentuate aspects of a study out of context ("cherry picking"), or may misrepresent variables, findings or data analyses out of ignorance or misunderstanding. These errors are then copied from one author to the next, and - like the telephone game - the story changes down the line. Something important gets lost in translation, and it is no longer remembered what the study was once truly about or what it reported. Often this process occurs from natural selection or disintegration over time. However, it can also occur when deliberate or inadvertent biases creep into the research process in order to make it more pertinent in the legal process. As a result, studies get used for purposes other than what they were intended, and the politicization of the process renders the research misleading and ultimately of limited or distorted value. When research is made a tool for advocacy, results are emphasized that support a particular view, while contrary findings or studies that refute the policy goal are ignored.

\section{Static versus dynamic view of parenting}

When applied judiciously to a set of circumstances, research provides valuable information about how a set of events or dynamics may turn out for a child or family, given statistical probabilities. They cannot offer probabilities about how a living arrangement is likely to turn out for a family in the future, unless all of the factors that might affect that outcome are also taken into consideration. Nor can research foresee a change in the family's direction. For example, 
how two parents are getting along eight months after separation gives us a better than chance occurrence that they will co-parent the child cooperatively two years later. We have an even greater basis for prediction if they had a positive relationship before the separation. However, that history may lose its predictive force if one or both parents form a new union that impacts the co-parental bond for better or worse; what happens in the new relationships may alter one or both parents' desire or ability to be involved with the children from the separated family. This raises the question whether post-separation parenting policy should ensure a process for re-assessing post-separation parenting arrangements since they often evolve in unpredictable ways. In terms of shared parenting presumptions, the central question is whether they support consistency at the cost of flexibility, both at the time of the separation and as the child and family change over time.

In sum, research cannot fully bridge the gap between science and the needs of the legal system. The intersection of science (inherent questioning and uncertainty leading to tentative findings) and legal process (inherent certainty in presentations leading to definitive rulings) defines the disparity between what family law research is equipped to do and what it is asked to do. Closing this gap requires that both legal and social science professionals strive for consensus in using research to further family law policies in the best interests of children and families.

\section{Presumptions and Factors about Shared Parenting and Joint Decision-Making}

Family law generally endeavors to strike a delicate balancing act between a) finding individualized solutions for each family and b) promulgating rules, guidelines and presumptions to provide separating parents with "starting points" for their individual determinations. After considering the way in which shared parenting serves as a lynchpin for policy, practice, and 
research controversies, the Think Tank participants summarized the desirability of presumptions and factors, and considered the research each supported.

\section{Presumptions}

Consensus Point 7. Supporting self-determination by parents whenever it is safe for the parents and children to do so is an optimal goal for professionals in family law.

- $\quad$ The family justice system should treat parents and children with fairness and respect that will support parents in determining how they will meet their children's needs.

- When asked or required to do so, courts should make decisions concerning parenting arrangements based on the specific and unique needs of individual children.

- Special circumstances and limiting conditions to parental self-determination require caution and specialized knowledge (empirical and clinical) in order to focus on the individualized circumstances that might affect child stability through shared parenting arrangements. They include the mental illness of a parent and the child's specific maturational, medical, social or educational needs. In these situations, the emphasis placed on the child's needs for stability and trust, the parents' ability to co-parent and communicate, and each parent's availability and consistency must be attended to with vigilance.

- If the court determines that one or both parents have committed one or more acts of domestic violence, the court should make an individualized determination regarding parenting arrangements. The ability of one or both parents to reflect on and repair relationships after the domestic violence should be taken into account, along with other relevant factors.

Consensus Point 8. A majority of Think Tank professionals supported a presumption of joint decision-making, while the rest supported a case-by-case approach. Even with a joint-decision making presumption, the factors that trigger individual determinations (e.g., domestic violence) remain to be fully delineated. 
- It was also recognized that joint decision making is already common across many countries and jurisdictions, and can more easily be circumscribed and managed for many families than can shared parenting time.

Consensus Point 9. Determinations about parenting time after separation that involve third parties (mental health, legal) are inescapably case-specific.

- Research informs areas of inquiry and illuminates key considerations for determining the most appropriate parenting arrangements for particular families. However, research cannot prescribe caregiving arrangements suitable for all families in all situations.

Consensus Point 10. Children's best interests are furthered by parenting plans providing for continuing and shared parenting relationships that are safe, secure, and developmentally responsive, and which avoid a template calling for a specific division of time imposed on all families.

- Shared parenting presumptions may support both parents' involvement, but when parents are unable to manage their conflict appropriately, that very involvement may aggravate the conflict to the child's detriment.

- It is inappropriate to have a presumption that covers all situations when not enough is known to verify that the presumption will benefit almost all children and families. Presumptions appear in the law as a blunt instrument, yet we know very little empirically about how a presumption would apply to same sex couples, non-biological parents, never marrieds who had no significant partnership before having a child together, and so on.

- In particular, the highly unique circumstances, needs, and developmental trajectories of young children in separating families counsel convincingly for the rejection of any presumptions either for or opposed to overnights or regarding a specific amount of contact with each parent. We simply do not have the science to support such precise presumptions.

Consensus Point 11. In lieu of a parenting time presumption, a detailed list of factors bears consideration in each case. These relevant factors, which generally comprise the best interests standard, by and large cut across age and special circumstances. They 
delineate the major aspects of personal, dyadic, and environmental interactions and conditions that affect development, as demonstrated by empirical evidence and clinical knowledge from the social sciences.

\section{Factors}

Having agreed upon the importance of taking factors into account to individualize shared parenting determinations, Think Tank participants listed the relevant factors. The list that follows is extensive but not all-inclusive. The categories generally apply to all age children, although some specifics will differ based on the age and developmental stage of the child or other familial circumstances. Not all of these factors are based on similar amounts or quality of science. Most have some empirical support, while others are informed more substantially from clinical experience.

Qualities of the infant/child: need to develop secure attachments with significant caregivers, need to develop self-regulatory mechanisms which are associated with sensitive and consistent caregiving, breast-feeding circumstances if applicable, temperament, age, maturity level, response to separations and transitions, current routines, cognitive strengths, and any particular physical, emotional, educational, or other needs resulting from developmental stage or characteristics of the child.

Qualities of the parent: temperament (fit with child's temperament), parent's mental health (including mental illness, substance use or abuse); sensitivity to child's early developmental needs, capacity and willingness to be flexible as child's needs get expressed in the moment and change over time, capacity and interest in effecting cooperation in child-rearing domains and economic resources;

Nature of each parent-child relationship: warmth, availability, ability to correctly discern and respond sensitively to the child's needs, past experience living with the child and caregiving 
history, caregiving interest and motivation, and history of perpetrating child physical or emotional abuse or neglect;

Quality of the co-parenting relationship: capacity and willingness to be flexible as child's needs get expressed in the moment and change over time, level and nature of conflict and/or domestic violence (history, recency, intensity, frequency, content, and context (separationspecific or broader), competence to encapsulate the conflict and protect the child from exposure, ability to communicate appropriately and in a timely manner about the child, degree of facilitative versus inhibitive gatekeeping behavior, and capacity for cooperation about the child's developmental needs; and

Nature of the broader caregiving and cultural environment: proximity of parental homes, breast/bottle feeding arrangements, work schedules and circumstances, presence of extended kin or close friends that participate in caregiving, availability of additional childcare if needed and economic resources to it, and transition mechanics.

A fuller explication of these factors in light of empirical knowledge about each awaits more summarization and analysis than was addressed in the short time frame of the Think Tank conference. Some papers on these themes are forthcoming in current and future Family Court Review issues.

\section{Role of the Family Courts in Shared Parenting Dispute Resolution}

Our final Consensus Point captures the decision by Think Tank participants to align themselves with the movement to nudge parents in family disputes away from the adversarial process and toward dispute resolution alternatives. 
Consensus Point 12. Shared parenting arrangements may be supported or hindered by the legal processes that are intended to help parents separate. In order to maximize the court's potential to assist parents in achieving as much self-determination and collaboration as possible, both alternative dispute resolution (ADR) options and case management tools are strongly preferred.

- ADR processes are markedly better than litigation for separating parents and their children. Mediation is desirable for families who have not attempted $A D R$. These dispute resolution options are preferred to litigation, with the exception of some situations involving family violence or when a family member has been harmed, or when one parent contends that the other is substantially interfering with his or her access to their child, all of which require a careful assessment before determining appropriate strategies.

- Court case management is highly desirable as part of the ADR process. This would include a dedicated family court, the assignment of one judge throughout each family's process, and built-in follow-up where families have a place to return to court to assess how their arrangements are holding, or to seek changes if safety becomes an issue or enforcement becomes necessary.

The Think Tank also recognized that unresolved issues abound about the family court's role vis-à-vis parental self-determination. Bringing clarity to these issues in the future will help create consistent decisions across courts and geographical locations. Most pressing is the question of whether a judge should be able to overturn parental decisions, and on what basis? Should a judge be allowed to set aside a parenting agreement only on the ground of manifest injustice? Or should a judge also set aside agreements that they find not to be in the child's best interests? Would such a decision rest on the judge's view about whether the agreement is not sufficiently protective of one or both parties' own best interests? Are these decisions best left to relatively unfettered judicial discretion or should some stricter legal standards be developed? 


\section{Future Research}

The Think Tank participants shared more agreement about the value and limitations of social science research for family law pertaining to separation and divorce than we might have expected, given the diversity of views and professional roles represented in the group. Through the conversation, certain themes were reiterated, leading to a statement of research priorities for the future.

\section{Shared parenting arrangements}

- What parenting plans are most widely implemented and in which situations? Do these plans hold over time or are they modified in light of evolving developmental stages or family transitions?

- How are children faring in different types of arrangements over time?

- How is age a factor in children's adjustment to various shared parenting arrangements?

- Do shared parenting plans that are mandated have the same benefits as those that are voluntarily agreed to? For whom, and under what conditions?

- What types of arrangements maximize sensitive and responsive parenting in the immediate aftermath of the legal decision and in the longer term?

- What are children's views of living in different types of arrangements?

- Does shared parenting discourage parent-child coalitions against the other parent? 


\section{Parent involvement}

- What types of arrangements, both legal and residential, support non-residential parent involvement for those who are reluctant to be involved? Can certain arrangements encourage involvement?

- How can gatekeeping interventions help parents facilitate, or prevent parents from obstructing, the ongoing involvement of a previous partner/parent?

- Do statutes that express a minimum percentage of time due each parent provide protection for parents that cannot otherwise stay involved? On the other hand, would these explicit time prescriptions lock unwilling parents into unremitting conflict? What wording in statutory time specifications best accomplishes the policy goal of keeping non-residential or less-seen parents involved in children's lives after separation?

- What are the feedback mechanisms, and the directional influences, between shared parenting arrangements and parental involvement? For instance, does shared parenting (and what types and to what degree) stave off a sense of loss, anger or being treated unfairly following separation?

- To what extent do shared parenting arrangements help cement vulnerable parent-child ties?

- How are cultural differences accounted for in parenting plan arrangements? How do they impact the outcomes for children? What types of norms (familial, cultural, community) influence how shared parenting roles play out in families? 


\section{Young children and overnights}

- How much separation constitutes an undue hardship for children at very young ages? What types of relationships with the other parent/care giver serve as protective factors?

- How much of child outcomes can be explained by variables such as age or gender after conflict is accounted for? Under what circumstances does the co-parenting relationship trump age as the factor likely to enhance children's developmental stability rather than undermine it? Are there as-yet undetermined factors that must be explored?

- How do emotion regulation, attachment, day care and school adjustment, and child socialization stack up as goals for understanding the influence of shared parenting and parenting plan variables?

- When we look at overnights, what other factors must be included in our studies, such as temperament, schedule consistency, cultural norms, etc.?

\section{Domestic violence/IPV}

- How can both parents' involvement be supported without compromising the safety of any family member?

- What types of screening and assessment instruments best serve decisions made about whether shared parenting is desirable for individual families?

- What types of evidence-based interventions can be utilized when shared parenting is being considered? Can some arrangements be tried more effectively only when certain kinds of supports and treatments are available and in place? What are those? 


\section{Family court processes}

- Do states with formal policies calling for frequent and meaningful post-separation contact implement different parenting plan arrangements than those who do not? Does this statutory guidance result in particular normative time allocations? How do these state outcomes differ from those that specify a minimum time allocation?

- Do temporary parenting orders foster stability or lock in a perhaps inappropriate status quo?

\section{Conclusion}

This report represents but a first step in the process of thinking through how research, policy and practice about shared parenting can be more effectively integrated. Think Tank participants broadly agreed that the child's best interests, including health, safety, and welfare, are the paramount considerations in decision-making and parenting time determinations. Getting to consensus in policy is an ongoing conversation that will evolve as our knowledge base grows. Separating and divorcing families stand to benefit most if we can narrow the gap between social science research and family law policy and practice. As the professionals guiding these families, we too will benefit from a more cohesive integration. This report endeavors to present some thoughtful reflection and to provide some points of consensus that will hopefully lead to new models for comprehending the issues, research that fills in some of the current gaps, and recommendations that follow from the whole of what we come to understand about shared parenting. Shared parenting encompasses both danger and delight. We believe that, when all potential hazards are addressed, shared parenting offers unparalleled opportunities for families to 
reorganize and sustain their better selves after separation to ensure that children continue to be nurtured by parents whose collaboration sets a path for a strong family future.

\section{References}

Amato, P. R. \& Dorius, C. Fathers, children, and divorce. (2010). In M.E. Lamb (ed.), The role of the father in child development (pp. 177-200). Hoboken, NJ: Wiley \& Sons.

Bauserman, R. (2002). Child adjustment in joint-custody versus sole-custody arrangements: A meta-analytic review. Journal of Family Psychology, 16(1), 91-102.

Bailey, A. (2013). Prioritizing child safety as the prime best-interest factor. Family Law Quarterly, 47(1), 35-64.

Brinig, M., Drozd, L. \& Frederick, L. [THIS ISSUE]

Coontz, S. (2006). Marriage, A history: How love conquered marriage. New York: Penguin.

DiFonzo, J. H., et al., [THIS ISSUE]

Fabricius, W., Braver, S., L. Diaz, P. \& Velez, C.E. Custody and parenting time: Links to family relationships and well-being after divorce. In M.E. Lamb (ed.), The role of the father in child development (pp. 201-240). Hoboken, NJ: Wiley \& Sons.

Hannah, M.T. \& Goldstein, B. (2010). Domestic violence, abuse, and child custody: Legal strategies and policy issues. Kingston, NJ: Civic Research Institute.

Hardesty, J.L., Haselschwerdt, \& Johnson, M.P. Domestic violence and child custody. In In K. Kuehnle and L. Drozd (eds.), Parenting Plan Evaluations: Applied Research for the Family Court (pp. 442-478). Cambridge, UK: Oxford University.

Johnston, J.R. \& Ver Steegh, N. (2013). Historical trends in family court response to intimate partner violence: perspectives of critics and proponents of current practices. Family Court Review 51(1), 63-73.

Kelly, J. B. (2007). Children's living arrangements following separation and divorce: insights from empirical and clinical research. Special issue: Divorce and Its Aftermath. Family Process, 46(1), 35-52. pp. 35-52. 
Kline Pruett, M. \& Barker, R. (2009). Joint Custody: A judicious choice for families - but how, when, and why? In R. M. Galatzer-Levy and L. Kraus (Eds.), The scientific basis of custody decisions ( $2^{\text {nd }}$ ed., pp. 417-462). New York: Wiley.

Kline Pruett, M., Ebling, R. \& Insabella, G.M. (2004). Critical aspects of parenting plans for young children: Interjecting data into the debate about overnights. Family Court Review, 42 (1), $39-59$.

Kline Pruett, M., Cowan, C.P., Cowan, P.A., \& Diamond, J. S. (2011). Supporting father involvement in the context of separation and divorce. In K. Kuehnle \& L. Drozd (Eds.), Parenting plan evaluations: Applied research for the family court (pp. 123-154). Oxford, U.K.: Oxford University Press.

Kuehnle, K \& Drozd, L. (2012). Parenting Plan Evaluations: Applied Research for the Family Court. Cambridge, UK: Oxford University.

McIntosh, J., Kline Pruett, M. \& Kelly, J. [THIS ISSUE]

McIntosh, J., Smyth, B., Kelaher, M., Wells, Y. \& Long, C. (2010). Post separation parenting arrangements: outcomes for infants and children. Sydney, Aus: Australian Government Report.

Sandler, I. N., Wheeler, C.A \& Braver, S.L. (in press). Relations of parenting quality, interparental conflict, and overnights with mental health problems of children in divorcing families with high legal conflict. Journal of Family Psychology.

Solomon, J. \& George, C. (1999). The effects on attachment of overnight visitation in divorced and separated families: A longitudinal follow-up. In J. Solomon \& C. George (eds.), Attachment disorganization. New York: Guilford, 243-264.

Ver Steegh, N. \& Dalton, C. (2008). Report from the Wingspread Conference on domestic violence and family courts. Family Court Review, 46(3), 454-75.

\section{Appendix A}

\section{Think Tank Contributors}

Conveners: Arnold Shienvold, Ph.D. (Co-Chair), Peter Salem, M.A. (Co-Chair), Marsha Kline Pruett, Ph.D., M.S.L. (Co-Reporter), J. Herbie DiFonzo, J.D., Ph.D. (Co-Reporter), Bernie Mayer, Ph.D. (Facilitator), Loretta M. Frederick, J.D. (Steering Committee), Hon. Ramona Gonzales (Steering Committee), Stacey Platt, J.D. (Steering Committee), and Kyle D. Pruett, M.D. (Steering Committee). 
Participants: Nicholas Bala, J.D., Lawrence Jay Braunstein, J.D., Margaret F. Brinig, J.D., Bud Dale, J.D., Ph.D., Robin Deutsch, Ph.D., Hon. Grace G. Dickler, Leslie Drozd, Ph.D., Robert Emery, Ph.D., William V. Fabricius, Ph.D., Hon. William Fee, Jonathan Gould, Ph.D., Linda Fieldstone, M.Ed., Hon. Dianna Gould-Saltman, Grace M. Hawkins, LCSW, Leslye Hunter, LMFT, Janet R. Johnston, Ph.D., Joan B. Kelly, Ph.D., Jennifer McIntosh, Ph.D., Anne Menard, Irwin Sandler, Ph.D., Andrew Schepard, J.D., Richard A. Warshak, Ph.D., and Justice R. James Williams.

Invited but unable to attend: Chief Justice Diana Bryant (Family Court, Australia), Jean Clinton, M.D., Justice Rebecca Love Kourlis (Colo. Sup. Ct., ret.), Michael Lamb, Ph.D., Robert Marvin, Ph.D., and Leslie Ellen Shear, J.D.

\section{Appendix B}

\section{Points of Consensus Reached at the Think Tank}

Consensus Point 1: Promotion of shared parenting constitutes a public health issue that extends beyond a mere legal concern. Parents who collaborate in child rearing have a positive effect on their children's development and well-being. Parents who engage in protracted and/or severe conflict that includes rejecting or undermining the other parent have a negative impact. The potential for shared parenting is present for children regardless of the family structure in which they live, and it represents a key protective factor in (a) helping children adjust to separation and divorce and $(b)$ establishing an ongoing healthy family environment in which to rear children and facilitate high quality parenting.

Consensus Point 2: At its most influential, research evidence offers legal professionals and clinical decision makers the best available information without providing answers or predictions in any individual case. When aggregate-level research is applied as determinative of a specific case outcome, its value becomes compromised in the adversarial process.

Consensus Point 3: We need to differentiate areas with sufficient research to offer consensus in legal situations from those without a sufficient data basis or agreement about its interpretation. Only then can consumers of research distinguish the quality of individual studies and the authority of an aggregate body for assisting in decisions. 
Consensus Point 4. Infancy is an important time of rapid growth and foundational development. During this time, sensitive caregiving is critical to maximize the child's immediate and long-term well-being. Special consideration needs to be given to meeting young children's developmental needs.

Consensus Point 5. Children benefit from parents sharing in their upbringing throughout their life span, where appropriate, including in the earliest stages of life.

Consensus Point 6. When there is a dispute over the care of a young child's care, decision makers (including parents) should consider all relevant factors. No single factor trumps the influence and importance of the aggregate.

Consensus Point 7. Supporting self-determination by parents whenever it is safe for the parents and children to do so is an optimal goal for professionals in family law.

- The family justice system should treat parents and children with fairness and respect that will support parents in determining how they will meet their children's needs.

- When asked or required to do so, courts should make decisions concerning parenting arrangements based on the specific and unique needs of individual children.

- Special circumstances and limiting conditions to parental self-determination require caution and specialized knowledge (empirical and clinical) in order to focus on the individualized circumstances that might affect child stability through shared parenting arrangements. They include the mental illness of a parent and the child's specific maturational, medical, social or educational needs. In these situations, the emphasis placed on the child's needs for stability and trust, the parents' ability to coparent and communicate, and each parent's availability and consistency must be attended to with vigilance.

- If the court determines that one or both parents have committed an act(s) of domestic violence, the court should make an individualized determination regarding parenting arrangements. The ability of one or both parents to reflect on and repair relationships after act(s) of domestic violence should be taken into account, along with other relevant factors. 
Consensus Point 8. A majority of Think Tank professionals supported a presumption of joint decision-making, while the rest supported a case-by-case approach. A presumption in favor of joint decision-making is not appropriate in every case, and factors that trigger individual determinations (e.g., domestic violence, far distance from parental domiciles) remain to be fully delineated.

- It was also recognized that joint decision making is already common across many countries and jurisdictions, and can more easily be circumscribed and managed for many families than can shared parenting time.

Consensus Point 9. Negotiations and determinations about parenting time after separation that involves third parties (mental health, legal) is inescapably case-specific.

- Research informs areas of inquiry and illuminates key considerations for determining the most appropriate parenting arrangements for particular families. However, research cannot prescribe caregiving arrangements suitable for all families in all situations.

Consensus Point 10. Children's best interests are furthered by parenting plans providing for continuing and shared parenting relationships that are safe, secure, and developmentally responsive, and which avoid a template calling for a specific division of time imposed on all families.

- Shared parenting presumptions may support both parents' involvement, but they may also encourage insensitive parenting aggravated by ongoing parental contact.

- It is inappropriate to have a presumption that covers all situations when not enough is known to verify that the presumption will benefit almost all children and families. Presumptions appear in the law as a blunt instrument, yet we know very little empirically about how a presumption would apply to same sex couples, nonbiological parents, never marrieds who had no significant partnership before having a child together, and so on.

- In particular, the highly unique circumstances, needs, and developmental trajectories of young children in separating families counsel convincingly for the rejection of any presumptions either for or opposed to overnights or regarding a specific amount of 
contact with each parent. We simply do not have the science to support such precise presumptions.

Consensus Point 11. In lieu of a parenting time presumption, a detailed list of factors bears consideration in each case. These relevant factors, which generally comprise the best interests standard, by and large cut across age and special circumstances, as they delineate the major aspects of personal, dyadic, and environmental interactions and conditions that affect development, as demonstrated by empirical evidence and clinical knowledge from the social sciences.

Consensus Point 12. Shared parenting arrangements may be supported or hindered by the legal processes that are intended to help parents separate. In order to maximize the court's potential to assist parents in achieving as much self-determination and collaboration as possible, both alternative dispute resolution (ADR) options and case management tools are strongly preferred.

- ADR processes are markedly better than litigation for separating parents and their children. Mediation is desirable for families who have not attempted ADR. These dispute resolution options are preferred to litigation, with the exception of some situations involving family violence or when a family member has been harmed, or when one parent contends that the other is substantially interfering with his or her access to their child, all of which require a careful assessment before determining appropriate strategies.

- Court case management is highly desirable as part of the ADR process. This would include a dedicated family court, the assignment of one judge throughout each family's process, and built-in follow-up where families have a place to return to court to assess how their arrangements are holding, or to seek changes if safety becomes an issue or enforcement becomes necessary.

\footnotetext{
* Marsha Kline Pruett, PH.D., M.S.L., ABPP is the Maconda Brown O'Connor Chair at Smith School for Social Work and Adjunct Professor at Smith College, Department of Psychology. She conducts original research, designs and tests preventive interventions in courts and community agencies, consults nationally and internationally about family law issues, and maintains a small clinical practice that includes couples mediation and parenting plan consultation. Her books
} 
include Your Divorce Advisor (with D. Mercer) and Partnership Parenting (with K. Pruett). She has authored numerous articles, book chapters, and curricula; she is a frequent speaker and trainer for judges, attorneys, mental health professionals, and parents. Much of her work focuses on father involvement, co-parenting, and child adjustment.

* J. Herbie DiFonzo, J.D., Ph.D. is Professor of Law at the Maurice A. Deane School of Law at Hofstra University. He joined the academic world after practicing law (primarily family and criminal law) for 20 years. He is the author of BEYOND THE FAULT LiNE: THE LEGAL AND Popular Culture OF DivORCE IN TWENTIETH-CENTURY AMERICA. Recent articles include Breaking the Mold and Picking Up the Pieces: Rights of Parenthood and Parentage in Nontraditional Families; The Children of Baby M. (both with Ruth C. Stern) and How Marriage Became Optional: Cohabitation, Gender, and the Emerging Functional Norms. He and Ruth C. Stern are the authors of the forthcoming INTIMATE ASSOCIATIONS: THE LAW AND CULTURE OF FAMILIES IN TWENTY-FIRST CENTURY AMERICA.

${ }^{\mathrm{i}}$ This type of presumption is often referred to as a "rebuttable" presumption. Courts must adopt a rebuttable presumption as the decision in the case unless the party opposed to the presumption succeeds in overcoming it with sufficient evidence that a different allocation of decision-making would be in the child's best interest. By contrast, an "irrebuttable" presumption is a rule of law and cannot be overcome with evidence. All presumptions discussed in this Final Report are rebuttable.

${ }^{i i}$ Definitions of domestic violence, IPV, and/or abuse encompass a wide variety of behaviors. Depending on the jurisdiction, the proscribed conduct may include both physical and psychological harms. For example, the California Family Code sets out a presumption against awarding sole or joint legal or physical custody to a person who has "perpetrated domestic violence" within the past five years. The statute declares that

a person has "perpetrated domestic violence" when he or she is found by the court to have intentionally or recklessly caused or attempted to cause bodily injury, or sexual assault, or to have placed a person in reasonable apprehension of imminent serious bodily injury to that person or to another, or to have engaged in any behavior involving, but not limited to, threatening, striking, harassing, destroying personal property or disturbing the peace of another, for which a court may issue an ex parte order ... to protect the other party seeking custody of the child or to protect the child and the child's siblings.

Cal. Fam. Code Sec. 3044. A different provision (Sec. 3011) requires the court to consider "any history of abuse" by a parent as a factor in determining the child's best interests. Abuse in this context is defined to include "[i]ntentionally or recklessly to cause or attempt to cause bodily injury;" "[s]exual assault; "[t]o place a person in reasonable apprehension of imminent serious bodily injury to that person or to another;" and the following behaviors:

molesting, attacking, striking, stalking, threatening, sexually assaulting, battering, harassing, telephoning, including, but not limited to, making annoying telephone calls ..., destroying personal property, contacting, either directly or indirectly, by mail or otherwise, coming within a specified distance of, or disturbing the peace of the other party.... 
Cal. Fam. Code Secs. 6203, 6320.

By contrast, the New York Legislature established domestic violence as a factor for the court to consider in decision-making and parenting time proceedings. While the statute (N.Y. DRL $\S$ 240) does not define domestic violence, the legislative findings indicate that the statute is not limited to acts causing actual physical harm by referring specifically to "physical or psychological violence [used as] the means of control and the norm for the resolution of disputes." Child Custody and Visitation Proceedings-Domestic Violence as Factor, 1996 Sess. Law News of N.Y. Ch. 85 (A. 2446-C) (McKinney's). The legislature also declared that "[a] home environment of constant fear where physical or psychological violence is the means of control and the norm for the resolution of disputes must be contrary to the best interests of a child.” Id. See, e.g., J.D. v. N.D., 170 Misc. 2d 877, 882, 652 N.Y.S.2d 468, 471 (Fam. Ct. 1996):

Compelling proof of an unmistakable pattern of power and control exerted by the Petitioner against the Respondent emerged at this trial. Economic, verbal and sexual abuse, coupled with regular and frequent threats and intimidation, while more subtle in nature, are no less damaging than a physical blow. This panoply of factors is omnipresent in the case at bar. When taken together, they form the profile of a Respondent whose body may appear intact, but whose spirit has been pummeled and eroded by her husband's verbal aggression and psychological terror.

iii See, e.g., Ariz. Rev. Stat. Ann. § 25-401 (Joint legal decision-making means that "both parents share decision-making and neither parent's rights or responsibilities are superior except with respect to specified decisions as set forth by the court or the parents in the final judgment or order"); Cal. Fam. Code $\S 3003$ (Joint legal custody "means that both parents shall share the right and the responsibility to make the decisions relating to the health, education, and welfare of a child."); Utah Code Ann. § 30-3-10.1 (joint legal custody "means the sharing of the rights, privileges, duties, and powers of a parent by both parents, where specified").

${ }^{\text {iv }}$ In general, parenting plans aim at setting out the specific responsibilities of each parent in providing for the child's physical care and emotional stability, now and as the child ages and matures. The plans optimally cover decision-making and parenting time arrangements as well as specifics relevant to transitions between parents, changes in schedule, handling of future conflicts, agreements on cost sharing for child-related expenses beyond child support, etc. Parenting plans are discussed more thoroughly in the text at p. 13, infra.

${ }^{v}$ See, e.g., Mo. Ann. Stat. $§ 452.375(1)(3)$ (defining joint physical custody or parenting time as "an order awarding each of the parents significant, but not necessarily equal, periods of time during which a child resides with or is under the care and supervision of each of the parents. Joint physical custody shall be shared by the parents in such a way as to assure the child of frequent, continuing and meaningful contact with both parents..."; Utah Code Ann. § 30-3-10.1 (stating that joint physical custody or parenting time:

(a) means the child stays with each parent overnight for more than $30 \%$ of the year, and both parents contribute to the expenses of the child in addition to paying child support; 
(b) can mean equal or nearly equal periods of physical custody of and access to the child by each of the parents, as required to meet the best interest of the child;

(c) may require that a primary physical residence for the child be designated; and

(d) does not prohibit the court from specifying one parent as the primary caretaker and one home as the primary residence of the child.

Note that decision-making and parenting time are separate concepts. See Ariz. Rev. Stat. Ann. $\S$ 25-403.02 ("[s]hared legal decision-making does not necessarily mean equal parenting time"); Utah Code Ann. $§ 30-3-10.1$ (joint legal custody "is not based on awarding equal or nearly equal periods of physical custody of and access to the child to each of the parents, as the best interest of the child often requires that a primary physical residence for the child be designated"). But note also that "[a] parent who is not granted sole or joint legal decision-making is entitled to reasonable parenting time to ensure that the minor child has substantial, frequent, meaningful and continuing contact with the parent unless the court finds, after a hearing, that parenting time would endanger the child's physical, mental, moral or emotional health. Ariz. Rev. Stat. Ann. $§$ 25-403.01.

${ }^{v i}$ Note that the division is not solely gendered. Among same sex and non-traditional gender couples, divisions of labor occur and result in similar controversies after separation. 